\title{
A method to experimentally clamp leaf water content to defined values to assess its effects on apoplastic $\mathrm{pH}$
}

Hartmut Kaiser ( $\sim$ hkaiser@bot.uni-kiel.de )

Christian-Albrechts-Universität zu Kiel https://orcid.org/0000-0001-7133-046X

Amit Sagervanshi

Christian-Albrechts-Universität zu Kiel: Christian-Albrechts-Universitat zu Kiel

Karl H. Mühling

Christian Albrechts Universität zu Kiel: Christian-Albrechts-Universitat zu Kiel

\section{Research Article}

Keywords:

Posted Date: December 21st, 2021

DOI: https://doi.org/10.21203/rs.3.rs-1181568/v1

License: (c) (i) This work is licensed under a Creative Commons Attribution 4.0 International License.

Read Full License 
A method to experimentally clamp leaf water content to defined values to assess its effects on apoplastic pH

Authors:

Hartmut Kaiser ${ }^{1,2 *}$, Amit Sagervanshi ${ }^{1}$ and Karl H. Mühling ${ }^{1}$

\section{Addresses:}

${ }^{1}$ Institut für Pflanzenernährung und Bodenkunde

Christian-Albrechts-Universität zu Kiel

Hermann-Rodewald-Straße 2

D-24098 Kiel

Germany

${ }^{2}$ present address: Botanisches Institut und Botanischer Garten der Christian-AlbrechtsUniversität zu Kiel

Am Botanischen Garten 7

D-24098 Kiel

Germany

telephone: $+49+4318804293$

email: hkaiser@bot.uni-kiel.de

${ }^{*}$ corresponding author 


\begin{abstract}
Here, we present a method to control and manipulate leaf water content (LWC) of attached intact leaves enclosed in a cuvette by adjusting vapour pressure deficit (VPD) and consequently leaf transpiration. LWC is measured by a sensor based on IRtransmission and its signal processed to control a pump which circulates air from the cuvette through a cold trap thus forming a feedback-loop precisely controlling LWC. Constant LWC levels, step changes or ramps can be experimentally applied while measuring physiological responses. This technique is used in a combination with microscopic imaging of the lower leaf epidermis of Vicia faba to investigate responses to controlled LWC transients of apoplastic $\mathrm{pH}\left(\mathrm{pH}_{\mathrm{apo}}\right)$ as indicated by the excitation ratio of the $\mathrm{pH}$ sensitive dye OregonGreen.
\end{abstract}

\title{
Introduction:
}

Leaf water content (LWC) is one of the most important properties for biochemical functioning, growth, and plant survival. Therefore it is under tight physiological control by diverse mechanisms (Scharwies \& Dinneny, 2019). Regulation of LWC generally occurs via negative feedback loops. Deviations of LWC or related tissue properties like cell turgor are perceived and fed into signal transduction networks, finally resulting in physiological responses stabilizing an optimal LWC (Tardieu et al., 2018). Among other mechanisms, osmotic adjustment and modulation of hydraulic conductance (Vandeleur et al., 2014) serve to maintain a stable and beneficial level of leaf hydration (Turner, 2017). However, the most effective control over LWC is exerted by the adjustment of stomatal apertures and thus transpiration, which can quickly change the leaf water balance (Buckley, 2005; Brodribb \& McAdam, 2017). It is well established that stomatal guard cells respond to changing leaf hydration with osmotic adjustments, resulting in stomatal aperture changes. Whereas the signal transduction and membrane processes in guard cells are understood 
in depth (Assmann \& Jegla, 2016; Jezek \& Blatt, 2017), the intercellular signaling of water stress to guard cells is still partly obscure. The prominent role of abscisic acid in plant water homeostasis is evident, but other factors emerge as important alternative signaling agents or factors which modulate ABA-signaling (Malcheska et al., 2017). Apoplastic pH is hypothesized to play a role in signaling water stress within the tissue either directly or by changing the distribution between leaf compartments with different $\mathrm{pH}$ levels (Karuppanapandian et al., 2017; Geilfus, 2017; Geilfus et al., 2021). Important questions, however, are up to now unresolved. Especially the mechanisms behind the change of $\mathrm{pH}_{\text {apo }}$ in response to variations in $\mathrm{LWC}$ and the transduction of $\mathrm{pH}_{\mathrm{apo}}$ into cellular responses are unknown. Experiments targeting these questions are difficult because methods to experimentally manipulate leaf hydration in an exact and repeatable manner are lacking.

Research into the physiological and molecular feedback mechanisms of leaf water homeostasis usually involves an experimental treatment influencing leaf water status, measurements of intermediate physiological events and/or of the resulting effect on water flows and leaf hydration. In such experiments, the treatment should ideally and repeatably manipulate the property which serves as input into the feedback cycles. While it is not sure which one of the water-status related physicochemical properties are sensed in cells, be it e.g. turgor pressure, osmolarity or water potential, the absolute amount of water in the tissue is arguably a central property the experimenter should control precisely and repeatably. Unfortunately, direct control of LWC is hard to achieve. While it is easy to exactly define the external conditions which impact leaf water content like vapour pressure deficit, osmotic potential of solutions, soil water potential etc., the resulting LWC also depends on biological parameters, which are not under experimental control and can change during the experiment, like degree of stomatal opening. Therefore even if, e.g. VPD can be precisely and repeatably controlled, and be kept constant during the 
experimental period, the resulting LWC is subject to the varying balance of water uptake and transpirational flow dependent on stomatal responses, osmotic adjustment and variations in hydraulic conductivity. Therefore, LWC will vary between repetitions and be subject to uncontrolled change during the experiment. In the absence of a method to measure LWC, it will not even be known.

Here we present an experimental approach to precisely control LWC by feeding the signal of a recently developed optical LWC sensor into the humidity control loop of a cuvette to dynamically adjust air humidity levels necessary to maintain the desired LWC. Concomitant measurements of apoplastic $\mathrm{pH}$ by ratiometric fluorescence imaging (Mühling \& Sattelmacher, 1995; Geilfus \& Mühling, 2013) allow testing hypotheses regarding the role of apoplastic $\mathrm{pH}$ as a tissue signaling agent in leaf water homeostasis.

\section{Method}

Plants of Vicia faba var. Fuego (NPZ, Gettorf, Germany) used in these experiments were hydroponically grown in a climate chamber as decribed in more detail in (Sagervanshi et al., 2021). Fully expanded attached leaves of c. 3 weeks old plants were mounted in a humidity-controlled cuvette with glass bottom on top of an inverted microscope (iMIC, Thermo Fisher), allowing ratiometric fluorescence microscopy (Fig. 1, 2). Humidity control was achieved by streaming a constant flow of humid air into the cuvette and removing varying amounts of humidity with a cold trap (KF-18/2, Walz, Germany) arranged in a bypass flow which was driven by a variable flow pump (LD10G, Walz) (Fig. 1). A LWC sensor based on the IR transmission ratio in the near infrared range (for details see Kaiser 2021, Physiologia Plantarum, submitted, \#to be added in proof\#) continuously measured LWC near the pH measurement site (Fig. 2). LWC and VPD were continuously recorded by a datalogger (CR23x, Campbell Scientific). A proportional, integral and derivative (PID) feedback loop (Karl Johan Åström \& Hägglund, 1995) encoded into the same dataloggers 
program generated a variable voltage which controlled the bypass pump. This feedback signal depended either on-air humitity measured by a rH sensor (SHT31-A, Sensirion) in the cuvette or on deviations of LWC from experimental LWC setpoints. PID parameters were determined by trial and error to achieve rapid LWC adjustments with minimal overshoot. In-situ measurements of $\mathrm{pH}$ apo were performed using the ratiometric $\mathrm{pH}$ sensitive dye OregonGreen dextrane (Invitrogen D7170) (Geilfus \& Mühling, 2011). The dye $(50 \mu \mathrm{M})$ was injected into the apoplast with a blunt syringe the afternoon before the measurement to allow leaf acclimatization over night.

\section{Results and discussion}

The functioning of the experimental setup to control of LWC was demonstrated in a twopart experiment, contrasting conventional humidity control with feedback control of LWC (Fig. 3). First, a stepwise change in VPD from 0.3 to 0.9 for $1 \mathrm{~h}$ was performed, and the response of LWC observed. LWC responded to a sudden step-wise increase of VPD with an initial decline of LWC to a minimum at 10 min and a gradual recovery during the following 50 min, which, although not recorded in this experiment, can likely be attributed to stomatal closure. After $1 \mathrm{~h}$ LWC had substantially recovered under unchanged VPD. Upon return to low VPD, LWC returned to near saturation values within 10 min following a typical relaxation kinetics. Notably, although VPD was kept precisely constant during this part of the experiment, LWC displayed a complex dynamic response governed by perturbation and relaxation of the water balance and biological adjustment responses. For the experimenter it would be hard to predict the effect of VPD changes on LWC or to to carry out this treatment in a reproducible manner, as the effect of VPD on LWC depends on various unknowns, like the initial degree of stomatal opening and the stomatal response to this treatment.

This was the reason to reprogram the feedback loop to control LWC instead of VPD to 
values defined by the experimenter, by feeding the output of the LWC sensor into feedback control (Fig. 1). In this second part of the experiment shown in Fig. 3, feedback control of LWC was used to step-wise reduce LWC. The LWC changes were much faster and occurred within minutes lacking most of the slur observed under feed-back control of VPD. During the $1 \mathrm{~h}$ period, LWC was kept constant while VPD was adjusted in the way required to control LWC. This automatically compensated fo biological influences like changes of stomatal apertures (Fig. 1B). VPD in this experiment thus should no longer be seen as the experimental variable but as the means to achieve the desired LWC. The peaks and jitters observed in the VPD trace reflect the feedback loop's action necessary to stabilize LWC at the set-point. Strikingly, the compensatory action of the feedback loop is apparent in the gradual increase of VPD during the $1 \mathrm{~h}$ period, which was necessary to counteract the biological reactions of stomatal closure and possibly osmotic adjustment. More complex experimental manipulations of LWC are also possible. Programmed ramps of LWC were executed to slowly change LWC (Fig. 4). This experiment was designed to assess the effect of reductions in LWC on apoplastic $\mathrm{pH}$. It is well established that $\mathrm{pH}_{\text {apo }}$ responds to salinity, reductions osmotic stress and high VPD with substantial transient alkalization (Geilfus \& Mühling, 2013; Geilfus, 2017; Geilfus et al., 2021). These stresses however are comprised of sub-stresses (e.g. ionic, osmotic, dehydration) with different kinetics and amplitudes which are intransparent to the experimenter, hindering a clear causal assignment of the observed $\mathrm{pH}$ responses. The idea behind this experiment was to assess the $\mathrm{pH}_{\text {apo }}$ response to an experimentally isolated and repeatably controlled reduction in LWC. By slowly changing LWC allowing enough time for equilibration, it was attempted to derive a dose-response relationship between $\mathrm{LWC}$ and $\mathrm{pH}_{\text {apo. }}$. This experiment demonstrates firstly that more complex and methodologically useful transitions of LWC can be experimentally imposed. Additionally, the apparent co-variation of LWC and $\mathrm{pH}_{\text {apo }}$ demonstrates the usefulness of this non-invasive control technique to study 
functional relationships between delicate and easily disturbed properties in combination with other non-invasive measurements.

In summary, bringing LWC under experimental control helps to better assess its role as an input into signaling and regulatory processes. The conventional approach of varying LWC by changing external environmental variables, like VPD, suffers from the unpredictable physiological feedback of the research object. Stomatal responses and other homeostatic feedback responses will defy attempts to precisely and repeatably control LWC. The proposed method in contrast allows to truly treat LWC as an experimental factor to assess its effect on biological responses (e.g stomatal movements and osmotic adjustment) and putative intermediate signaling events like changes in $[A B A]$ and $\mathrm{pH}_{a p o}$.

\section{References}

Assmann SM, Jegla T. 2016. Guard cell sensory systems: recent insights on stomatal responses to light, abscisic acid, and $\mathrm{CO}_{2}$. Current Opinion in Plant Biology 33: 157-167. Brodribb TJ, McAdam SAM. 2017. Evolution of the stomatal regulation of plant water content. Plant Physiology 174: 639-649.

Buckley TN. 2005. The control of stomata by water balance. New Phytologist 168: 275292.

Geilfus C-M. 2017. The $\mathrm{pH}$ of the apoplast: dynamic factor with functional impact under stress. Molecular Plant 10: 1371-1386.

Geilfus C-M, Mühling KH. 2011. Real-time imaging of leaf apoplastic pH dynamics in response to $\mathrm{NaCl}$ stress. Frontiers in Plant Nutrition 2: 1-13.

Geilfus C-M, Mühling K-H. 2013. Ratiometric monitoring of transient apoplastic alkalinizations in the leaf apoplast of living Vicia faba plants: chloride primes and $\mathrm{PM}-\mathrm{H}^{+}-$ ATPase shapes $\mathrm{NaCl}$-induced systemic alkalinizations. New Phytologist 197: 1117-1129. Geilfus C-M, Zhang X, Mithöfer A, Burgel L, Bárdos G, Zörb C. 2021. Leaf apoplastic 
alkalization promotes transcription of the ABA-synthesizing enzyme Vp14 and stomatal closure in Zea mays. Journal of Experimental Botany 72: 2686-2695.

Jezek M, Blatt MR. 2017. The membrane transport system of the guard cell and its integration for stomatal dynamics. Plant Physiology 174: 487-519.

Karl Johan Åström, Hägglund T. 1995. PID Controllers: Theory, Design, and Tuning. Research Triangle Park, North Carolina: ISA - The Instrumentation, Systems and Automation Society.

Karuppanapandian T, Geilfus C-M, Mühling K-H, Novák O, Gloser V. 2017. Early changes of the $\mathrm{pH}$ of the apoplast are different in leaves, stem and roots of Vicia faba L. under declining water availability. Plant Science 255: 51-58.

Malcheska F, Ahmad A, Batool S, Müller HM, Ludwig-Müller J, Kreuzwieser J, Randewig D, Hänsch R, Mendel RR, Hell R, et al. 2017. Drought-enhanced xylem sap sulfate closes stomata by affecting ALMT12 and guard cell ABA synthesis. Plant Physiology 174: 798-814.

Mühling KH, Sattelmacher B. 1995. Apoplastic ion concentration of intact leaves of field bean (Vicia faba) as influenced by ammonium and nitrate nutrition. Journal of Plant Physiology 147: 81-86.

Sagervanshi A, Naeem A, Geilfus C-M, Kaiser H, Mühling KH. 2021. One-time abscisic acid priming induces long-term salinity resistance in Vicia faba: Changes in key transcripts, metabolites, and ionic relations. Physiologia Plantarum 172: 146-161.

Scharwies JD, Dinneny JR. 2019. Water transport, perception, and response in plants. Journal of Plant Research 132: 311-324.

Tardieu F, Simonneau T, Muller B. 2018. The physiological basis of drought tolerance in crop plants: A scenario-dependent probabilistic approach. Annual Review of Plant Biology 69: 733-759.

Turner NC. 2017. Turgor maintenance by osmotic adjustment, an adaptive mechanism for 
coping with plant water deficits. Plant, Cell \& Environment 40: 1-3.

Vandeleur RK, Sullivan W, Athman A, Jordans C, Gilliham M, Kaiser BN, Tyerman

SD. 2014. Rapid shoot-to-root signalling regulates root hydraulic conductance via aquaporins. Plant, Cell \& Environment 37: 520-538.

\section{Declarations}

Ethics approval and consent to participate

Not applicable

Consent for publication

Not applicable

Availability of data and material

All data generated or analysed during this study are included in this published article in graphical form. The numerical datasets generated during and/or analysed during the current study are available from the corresponding author on reasonable request.

Competing interests

The authors declare that they have no competing interests

\section{Funding}

The microspectrofluorimeter (iMIC) was funded by the German Research Foundation (Grant INST 257/449-1 FUGG to KHM)

Authors' contributions 
HK developed the method of LWC clamping, designed and performed the experiments, analysed the data and wrote the manuscript. AS implemented the measurements of apoplastic $\mathrm{pH}$ measurements, made substantial contributions to the conception and analysis of the results and to the writing of the manuscript. KHM made substantial contributions to the conception of the work and substantially revised the manuscript. All authors have approved the submitted version and have agreed both to be personally accountable for the author's own contributions and to ensure that questions related to the accuracy or integrity of any part of the work, even ones in which the author was not personally involved, are appropriately investigated, resolved, and the resolution documented in the literature.

\section{Acknowledgements}

We gratefully acknowledge the funding of the microspectrofluorimeter (iMIC) by the German Research Foundation (Grant INST 257/449-1 FUGG to KHM). 


\section{Figures}
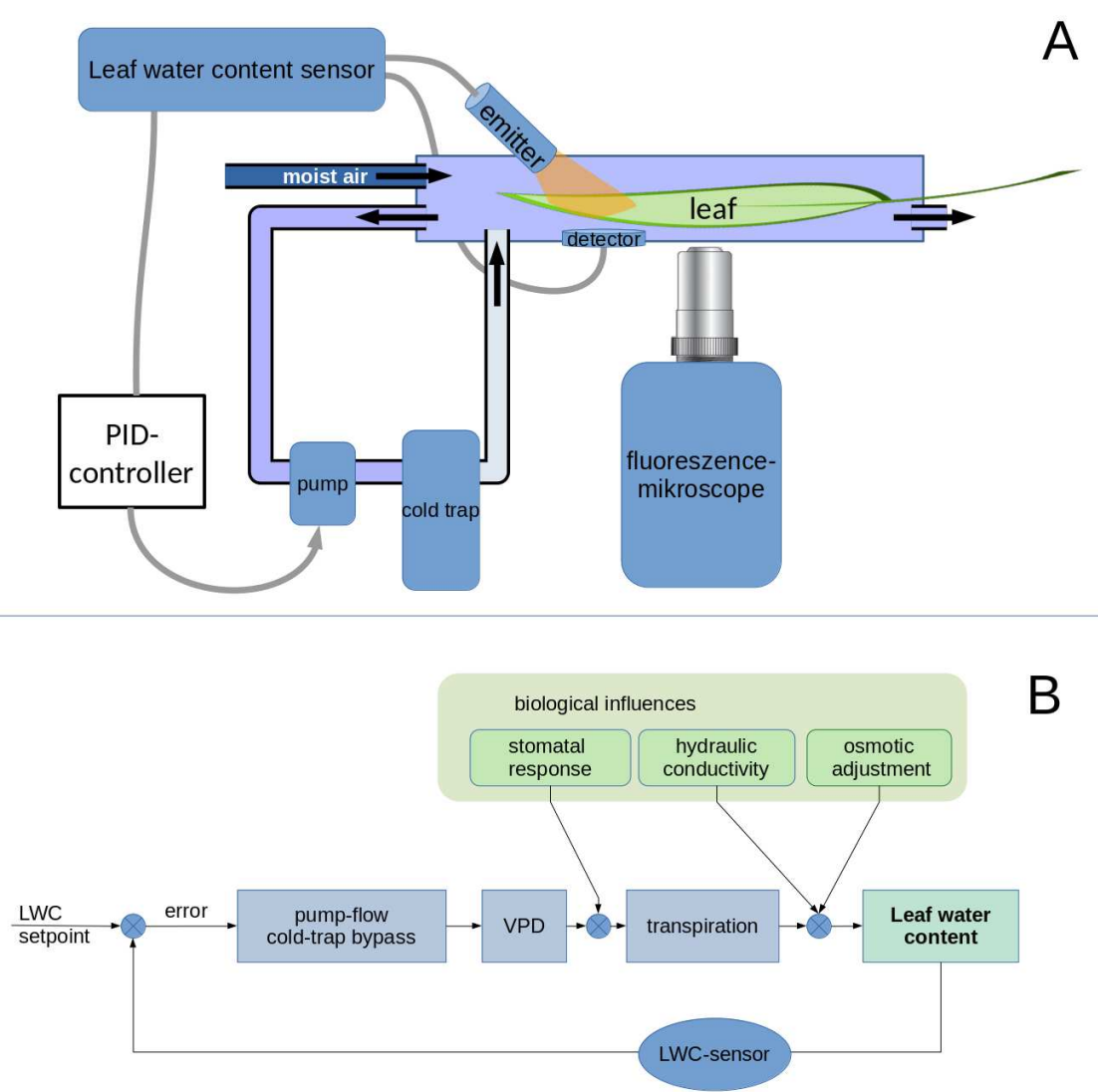

Fig. 1

A. Scheme of the experimental setup and feedback loop.

B. control diagram of the feedback loop controlling LWC by using the LWC sensor's output to control the pump in the drying bypass loop. Biological regulators of leaf water homeostasis (green boxes) modify the effect of VPD on LWC. Stomatal responses determine the effect of VPD on transpiration while hydraulic conductivity and osmotic adjustment modulate the effect of transpiration on the leaf water balance and thus LWC. The varying effect of these biological influences is compensated for by continuous adjustment of VPD. 


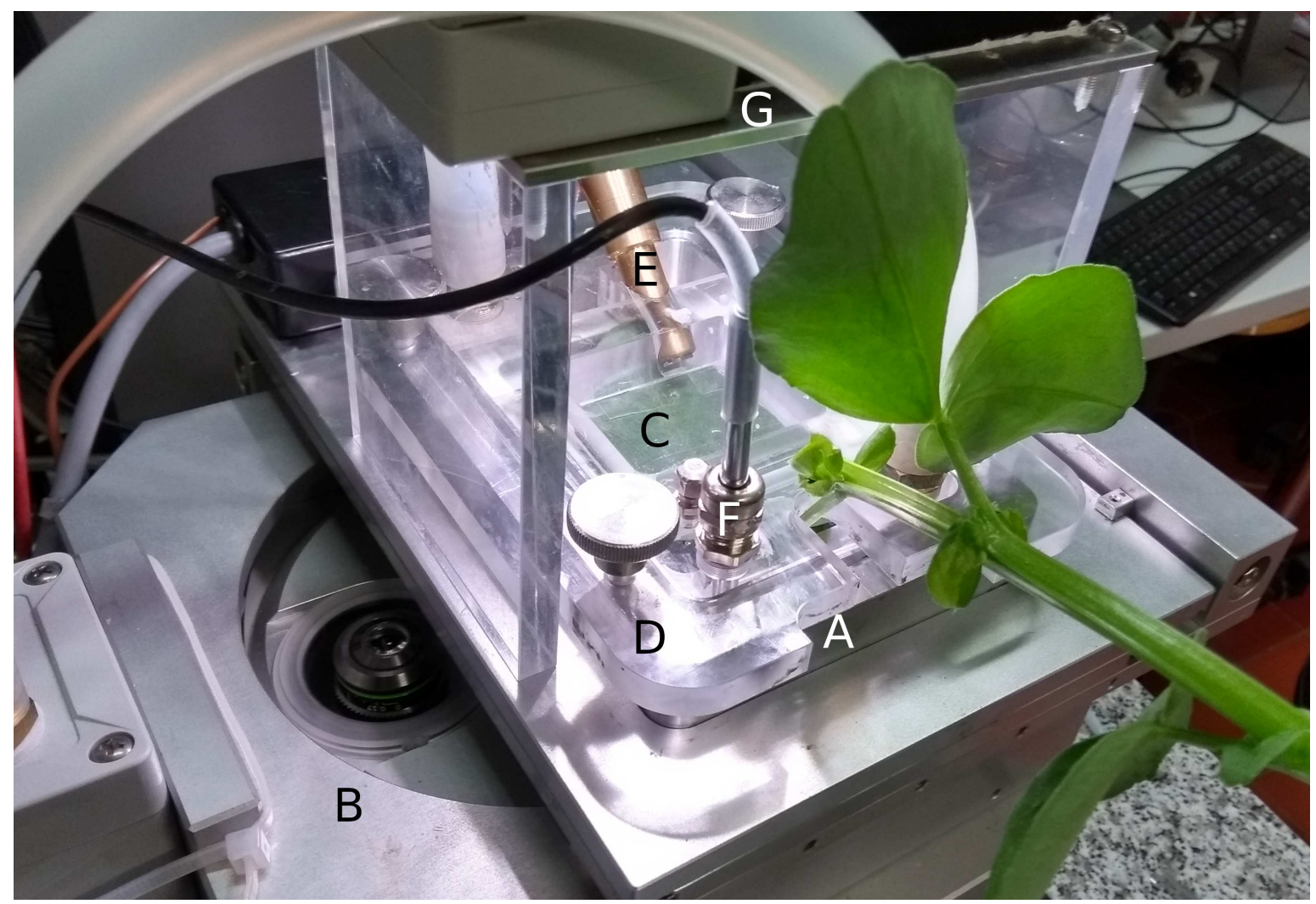

Fig. 2

Cuvette for control of leaf water content of the enclosed leaf. The cuvette $(A)$ is installed on the motorized stage of an inverted fluorescence microscope (B). The enclosed leaf (C) is attached to the transparent (D) lid of the cuvette with double sided tape and microscopically observed through the glass bottom made of cover slide glass. A leaf water content sensor comprised of a dual IR-LED light source (E) and a photo-diode (not visible) below the leaf-surface continuously tracks LWC. Its output is fed into a feedback algorithm which controls VPD of the air passing over the leaf surface. Alternatively VPD can be feed-back-controlled according to the output of a air humidity sensor (F). Illumination is provided by a switchable white LED light source under the control of the microscope central unit, which can be switched off for about 120ms during fluorescence measurements. 


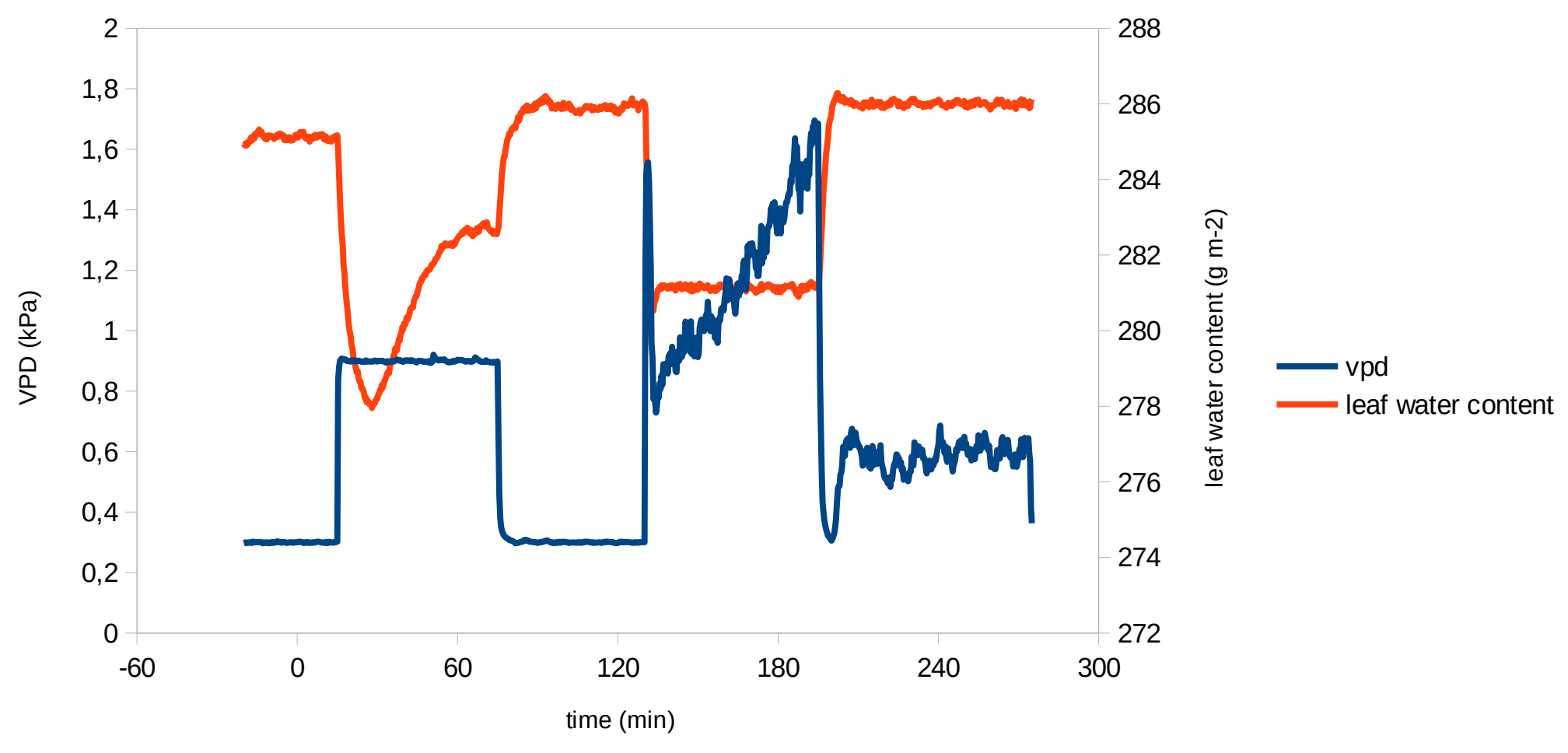

Fig. 3

Measurement of LWC and VPD during an experiment using first (0-120 min) feedbackcontrol of air humidity to perform a step change in air humidity and (120-280 min) feedback control of LWC to perform step changes of LWC. In the first part, leaf water content fluctuates dynamically as a result of changing leaf water balance. In the second part, LWC is fixed, and VPD is varied by feedback control as required to clamp LWC at constant set-points. 


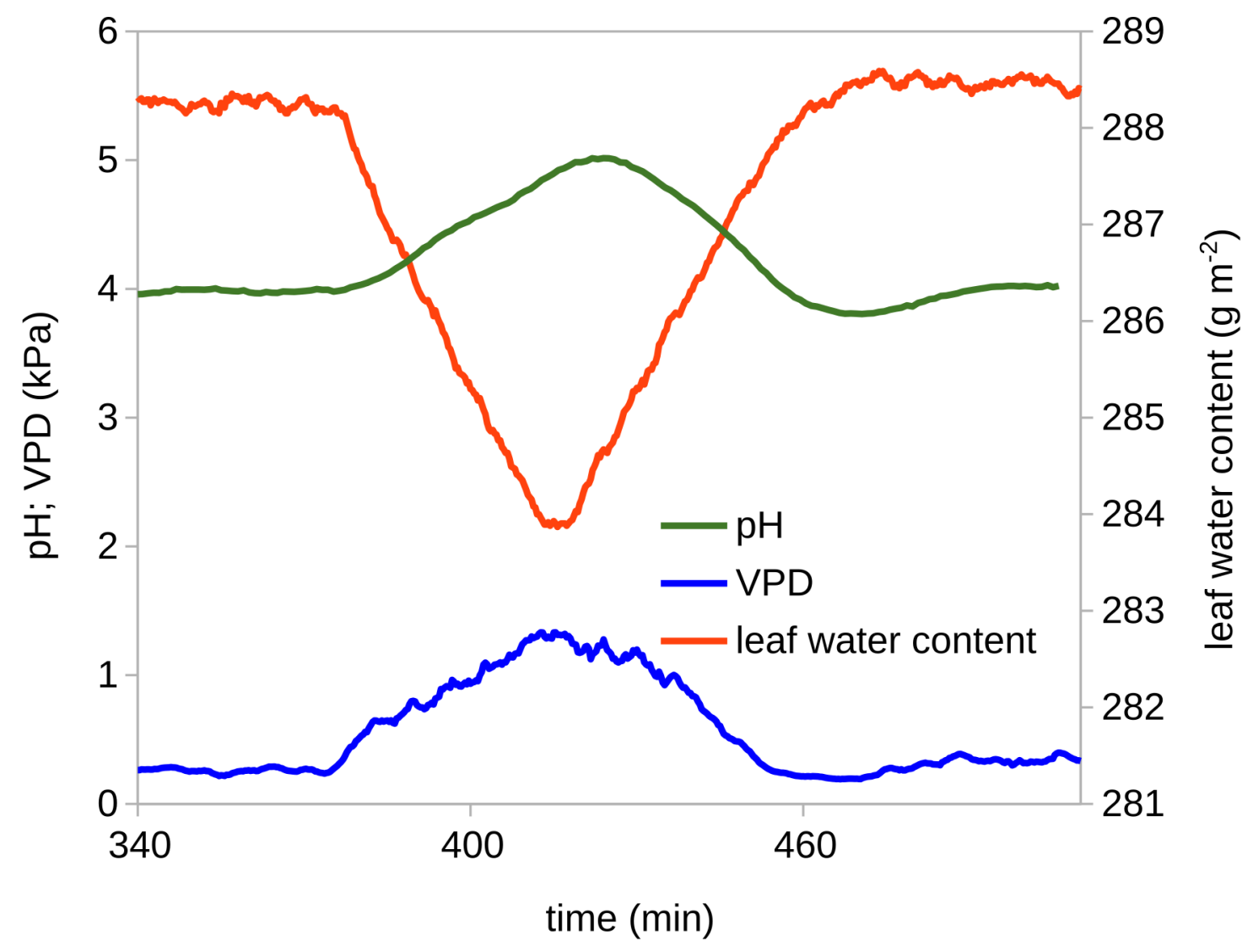

Fig. 4

Recording of apoplastic $\mathrm{pH}$ of the lower leaf epidermis by fluorescence ratio imaging using OregonGreen under feedback-controlled LWC. LWC set-point was varied by a programmed ramp to achieve a constant rate of change of LWC. 